\title{
PENGARUH KEKERINGAN PADA PRODUKSI TANAMAN PADI DI KABUPATEN MAJALENGKA DENGAN PENGINDERAAN JAUH METODE NDVI
}

\author{
Ni Ketut Feny P P,2,* , Mangapul P. Tambunan³, Masita Dwi Mandini Mannesa ${ }^{3}$, Rudy P.Tambunan ${ }^{3}$ \\ ${ }^{1}$ Mahasiswa Magister Departemen Geografi, Fakultas Matematika dan Ilmu Pengetahuan Alam, Universitas Indonesia \\ ${ }^{2}$ Badan Meteorologi Klimatologi dan Geofisika \\ ${ }^{3}$ Departemen Geografi, Fakultas MIPA, Universitas Indonesia \\ *Penulis Korespondensi : ni.ketut92@ui.ac.id
}

\begin{abstract}
Abstrak. Indonesia termasuk negara ketiga penghasil padi terbesar di Asia Tenggara. Pulau Jawa memiliki tiga provinsi penghasil padi terbesar yaitu Provinsi Jawa Barat, Jawa Tengah dan Jawa Timur. Sektor pertanian membutuhkan air untuk konsumsi tanamannya. Bencana kekeringan menyebabkan dampak negatif terhadap sektor pertanian dan hasil produksi tanaman padi. Penelitian ini dibuat berdasarkan Sistem Informasi Geografis (SIG), dengan menggunakan indeks vegetasi Normalized Difference Vegetation Index (NDVI), dan menggunakan data primer berupa data Citra Satelit Landsat 8. Pendekatan yang Metode Penginderaan Jauh ini menggunakan Google Earth Engine dalam mengolah koreksi awan dan Nilai NDVI. Penelitian ini bertujuan untuk menganalisa bagaimana hubungan antara NDVI bulanan dengan hasil produksi padi, dan data curah hujan. Hasil dari Penelitian ini adalah Tahun 2018 luas sawah yang mengalami panen padi adalah 11.019 ha dan pada Tahun 2019 adalah sebesar 10.985 ha. Kajian ini dilakukan sebagai bahan pertimbangan kepada pemerintah di Kabupaten Majalengka untuk mengestimasi waktu tanam dan panen padi melalui nilai NDVI dan menganalisis pengaruh dari nilai NDVI terhadap produksi padi curah hujan.
\end{abstract}

Kata Kunci: Kabupaten Majalengka; Citra Satelit Landsat-8; NDVI; produksi padi; curah hujan

\begin{abstract}
Indonesia is the third largest rice producer in Southeast Asia. Java Island has the three largest rice producing provinces, namely West Java, Central Java and East Java. The agricultural sector needs water for crop consumption. Drought disasters have a negative impact on the agricultural sector and rice production. This research was made based on the Geographical Information System (GIS), using the Normalized Difference Vegetation Index (NDVI) vegetation index, and using primary data in the form of Landsat 8 Satellite Imagery. NDVI. This study aims to analyze the relationship between monthly NDVI and rice production, as well as rainfall data. The results of this study are that in 2018 the area of rice fields that experienced rice harvest was 11,019 ha and in 2019 it was 10,985 ha. This research was conducted as a material consideration for the government of Majalengka Regency to estimate the planting and harvest time of rice through the NDVI value and to analyze the effect of the NDVI value on rainfall rice production. Keywords: Majalengka Regency; Landsat-8 Sattelite Image; NDVI; Rice Production; Rainfall
\end{abstract}

\section{PENDAHULUAN}

Indonesia merupakan negara yang menjadikan tanaman padi sebagai salah satu sumber pangan utama. Tiga provinsi di Pulau Jawa merupakan lumbung padi, ketiga Provinsi tersebut adalah Provinsi Jawa Barat, Jawa Tengah dan Jawa Timur. Selama dua tahun terurut yaitu Tahun 2018-2019, Provinsi Jawa Barat, menempati posisi ketiga produktivitas padi (Badan Pusat Statistik, 2020). Tanaman padi dinilai tanaman yang penting karena masyarakat Indonesia membutuhkan beras sebagai bahan makanan pokok. Masyarakat Indonesia kurang lebih sebesar 90\% menggunakan beras sebagai sumber makanan utama (Aji dkk., 2017).

Sektor pertanian membutuhkan air lebih dari 70\% untuk konsumsi tanaman-tanamannya (Pratiwi dkk., 2020). Air merupakan sumber daya alam yang dibutuhkan manusia. Pada musim hujan, air di beberapa wilayah Indonesia cenderung berlebih dan di beberapa daerah mengalami kesulitan air di musim kemarau (Prasetyo dkk., 2018). Bencana kekeringan menyebabkan dampak negatif terhadap sektor pertanian dan hasil produksi tanaman. Kekeringan merupakan tantangan global bagi 
masyarakat dunia dan pernah terjadi di seluruh negara (Widyastuti, 2020).

Salah satu wilayah di Jawa Barat yaitu Kabupaten Majalengka merupakan daerah yang mampu memproduksi padi selain Kabupaten Indramayu dan Kabupaten Subang. Kabupaten Majalengka terdiri dari topografi berupa pegunungan dengan ketinggian 500-857 meter di atas permukaan laut, daerah bergelombang / berbukit yang memiliki ketinggian $50-500 \mathrm{~m}$ di atas permukaan laut dan sisanya berupa daerah dataran rendah yang memiliki ketinggian 19-50 meter di bawah permukaan laut, kondisi ini menyebabkan bervariasinya kondisi vegetasi dan kondisi masingmasing daerah saat berkurangnya air di musim kemarau. Kabupaten Majalengka merupakan daerah dengan potensi pertanian yang mampu menghasilkan hasil pertanian berupa padi ataupun tanaman hortikultura berkualitas.

Penggunaan penginderaan jauh untuk monitoring tanaman padi mulai banyak dikembangkan (Dawe dkk., 2004; Shao dkk., 2001). Citra Satelit Landsat 8 merupakan citra satelit yang dapat digunakan untuk memonitoring padi (Ghaleb dkk., 2015; Iswari dkk., 2017; Khosravi dkk., 2017). Kajian ini menelaah bagaimana pengaruh kekeringan terhadap masa panen tanaman padi. Penelitian ini menggunakan metode pengolahan indeks vegetasi dengan NDVI (Normalized Difference Vegetation Index). Pengolahan citra satelit dengan metode NDVI dapat dilakukan dengan menggunakan Google Earth Engine, yang memudahkan dalam pemantauan vegetasi dengan cepat dan akurat (Julianto dkk., 2020). Karena keterbatasan data, penelitian ini mengambil waktu pada Tahun 2018 dan 2019 dengan lokasi penelitian di Kabupaten Majalengka. Penelitian ini bertujuan untuk melihat nilai NDVI bulanan di Kabupaten Majalengka kemudian mensitesa hubungan antara NDVI dengan hasil produksi padi dan curah hujan.

\section{METODOLOGI}

Lokasi penelitian terdapat di Kabupaten Majalengka dengan waktu penelitian Tahun 2018 dan 2019. Kabupaten Majalengka terletak di Provinsi
Jawa Barat yang terletak pada koordinat sebelah barat $108^{\circ} 03^{\prime}-108^{\circ} 19^{\prime} \mathrm{BT}$, titik koordinat di bagian timur $108^{\circ} 12^{\prime}-108^{\circ} 25^{\prime}$ BT, titik koordinat di bagian utara $6^{0} 36^{\prime}-5^{0} 58^{\prime}$ LS dan titik koordinat di bagian selatan $6^{\circ} 43^{\prime}-7^{\circ} 44^{\prime}$ LS. Luas wilayah dari Kabupaten Majalengka sebesar 1.204,24 km². Pada Gambar 1 ditunjukkan area sawah yang ada di Kabupaten Majalengka.

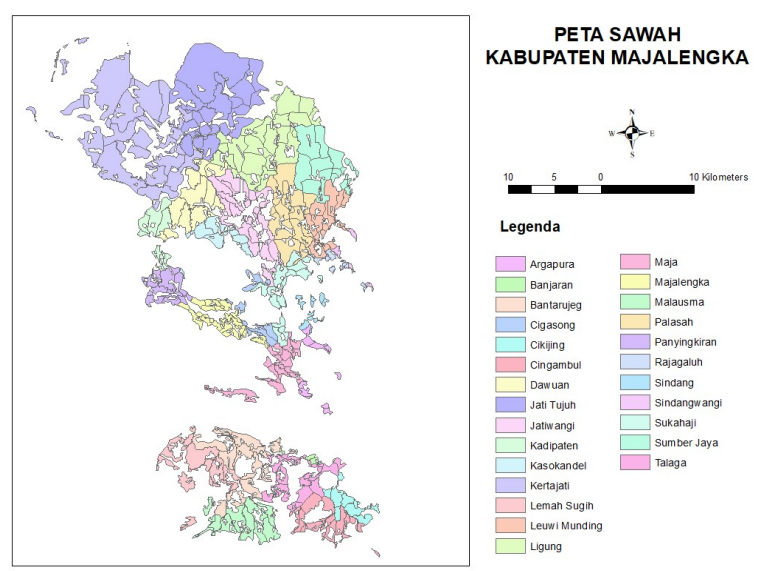

Gambar 1. Peta Sawah Kabupaten Majalengka

Citra Satelit Landsat-8 TOA Reflectance dari Google Earth Engine (GEE) adalah data primer yang digunakan pada penelitian ini. Citra Satelit Landsat-8 TOA Reflectance yang tersedia di GEE memiliki beberapa kelebihan antara lain (1) File efek cosinus dari puncak matahari telah terhapus (2) Reflektansi TOA dapat mengganti nilai yang berbeda dari radiasi matahari (3) Jarak dari Bumi-Matahari telah terkoreksi (Chander dkk., 2009). Koreksi radiometrik (menghilangkan awan) sebesar $25 \%$ dilakukan pada citra satelit Landsat-8, sebelum dihitung nilai NDVInya. Koreksi awan dipilih sebesar $25 \%$ karena citra satelit awan yang diperoleh dapat menggambarkan rentang waktu 5-6 bulan dalam satu tahun. Pada penelitian ini diperoleh 6 citra satelit di Tahun 2018 yaitu dari bulan Mei - Oktober dan 5 citra satelit di Tahun 2019 yaitu dari bulan Juli - November.

Dari Citra Satelit Landsat yang telah terkoreksi awan tersebut dihitung nilai NDVInya. Persamaan dalam menghitung Nilai NDVI dapat ditunjukkan sebagai berikut :

$N D V I=\frac{(N I R-R E D)}{(N I R+R)}$ 
Band RED merupakan band keempat dari citra Landsat-8 dan Band NIR merupakan band kelima dari citra Landsat-8. Nilai dari NDVI berkisar antara -1 dan 1.

Setelah menghitung nilai NDVI dilakukan Reklasifikasi nilai NDVI. Dari hasil reklasifikasi tersebut dihitung luas daerah pada setiap klasifikasinya. Rentang nilai NDVI yang digunakan pada kajian ini dapat ditunjukkan pada Tabel 1 (Adinda dkk., 2020).

Tabel 1. Rentang Nilai NDVI Sumber: (Menteri Kehutanan Republik Indonesia, 2012; Adinda dkk., 2020)

\begin{tabular}{cclll}
\hline Kelas & Nilai NDVI & \multicolumn{2}{c}{$\begin{array}{c}\text { Tingkat Kehijauan / Kondisi } \\
\text { Lahan }\end{array}$} \\
\hline 1 & $<-0,03$ & Lahan tidak bervegetasi \\
\hline 2 & $-0,03-0,15$ & $\begin{array}{l}\text { Lahan dengan Vegetasi Sangat } \\
\text { Rendah }\end{array}$ & \\
\hline 3 & $0,15-0,25$ & $\begin{array}{l}\text { Lahan dengan } \\
\text { Rendah }\end{array}$ & Vegetasi \\
\hline 4 & $0,26-0,35$ & $\begin{array}{l}\text { Lahan dengan } \\
\text { Sedang }\end{array}$ & Vegetasi \\
\hline 5 & $0,36-1$ & \multicolumn{2}{l}{ Lahan dengan Vegetasi Tinggi } \\
\hline
\end{tabular}

Data curah hujan dan data produksi padi adalah data sekunder yang digunakan pada kajian ini. Instansi BMKG membantu menyediakan data curah hujan yang dapat diakses melalui http://dataonline.bmkg.go.id/home, sementara itu data produksi padi diperoleh dari BPS melalui https://majalengkakab.bps.go.id/. Kedua data ini digunakan untuk melihat korelasi antara (1) NDVI dengan data produksi padi, jika nilai NDVI tinggi apakah menggambarkan produksi padi di suatu daerah tinggi begitupula sebaliknya (2) NDVI juga dibandingkan dengan data curah hujan, hal ini dapat menjelaskan apakah curah hujan berpengaruh terhadap NDVI suatu daerah. Gambar 2 menjelaskan alur kerja dari kajian ini.

Metode yang digunakan dalam penelitian ini adalah studi kasus dan deskriptif analisis. Penelitian studi kasus diterapkan untuk meneliti lebih dalam fenomena tertentu disuatu wilayah. Analisis deskriptif memiliki pengertian metode yang mampu menjelaskan gambaran dari objek yang tengah dianalisis berdasarkan data atau sampel yang tersedia, kemudian dilakukan analisis dan diperoleh kesimpulan (Huwaydi dan Persada, 2018). Pada penelitian ini peneliti mengumpulkan data primer, berupa Citra Satelit Landsat 8 , dan data sekunder yaitu data curah hujan dan data produksi padi. Tahapan yang dilakukan setelah pengumpulan data yaitu pengolahan data dan analisis bagaimana pengaruh kekeringan melalui indeks NDVI pada tanaman padi di Kabupaten Majalengka pada Tahun 2018 dan 2019.

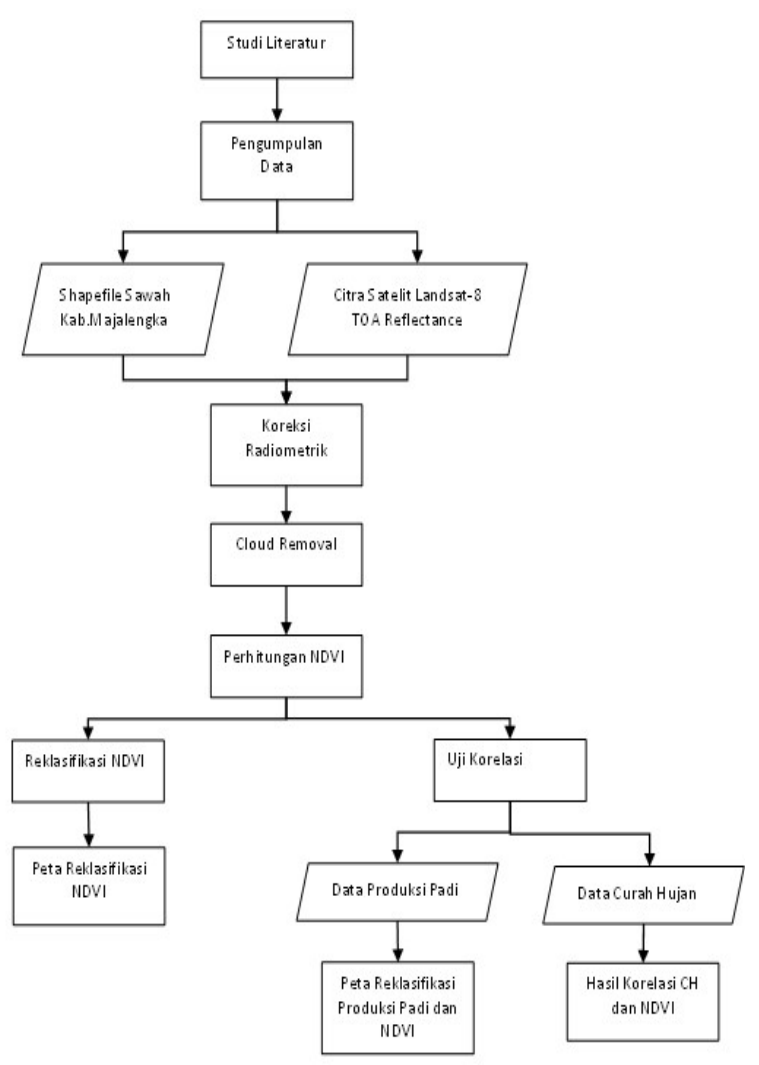

Gambar 2. Diagram Alur Kerja

\section{HASIL DAN PEMBAHASAN}

\section{Perhitungan Nilai NDVI}

Untuk menghitung nilai NDVI dari Citra Satelit Landsat-8, didapatkan dari Band RED (Band 4) dan Band NIR (Band 5). Perolehan Nilai NDVI dapat dilihat pada Tabel 2. 
Tabel 2. Nilai NDVI (Sumber: Hasil Analisis)

\begin{tabular}{ccccc}
\hline Thn & Bln & $\begin{array}{c}\text { NDVI } \\
\text { Min }\end{array}$ & $\begin{array}{c}\text { NDVI } \\
\text { Avg }\end{array}$ & NDVI Max \\
\cline { 2 - 5 } & \multicolumn{5}{c}{05} & -0.209 & 0.493 & 0.777 \\
\cline { 2 - 5 } 2018 & 06 & -0.519 & 0.672 & 0.824 \\
\cline { 2 - 5 } & 07 & -0.332 & 0,570 & 0.808 \\
\cline { 2 - 5 } & 08 & -0.506 & 0.662 & 0.818 \\
\cline { 2 - 5 } & 09 & -0.611 & 0.713 & 0.815 \\
\hline \multirow{3}{*}{2019} & 10 & -0.274 & 0.505 & 0.736 \\
\cline { 2 - 5 } & 07 & -0.160 & 0.457 & 0.754 \\
\cline { 2 - 5 } & 08 & -0.553 & 0.678 & 0.804 \\
\cline { 2 - 5 } & 09 & -0.181 & 0.481 & 0.781 \\
\hline & 10 & -0.395 & 0.592 & 0.789 \\
\hline
\end{tabular}

Berdasarkan Tabel 2, dapat diperoleh Grafik seperti pada Gambar 3, sebagai berikut.

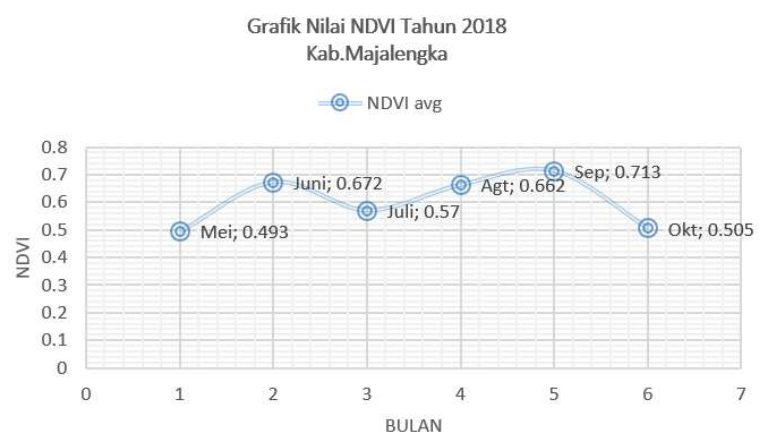

Gambar 3. Grafik NDVI Tahun 2018

Grafik NDVI Tahun 2018, dapat ditunjukkan Bulan Mei merupakan fase vegetatif awal padi, bulan Juni merupakan fase generatif, bulan Juli merupakan fase panen padi. Bulan Agustus dan bulan September merupakan fase pasca panen padi dimana, sawah dipersiapkan kembali untuk ditanami padi pada bulan November. Fase pertumbuhan tanaman padi berdasarkan nilai NDVI dapat ditunjukkan juga melalui data observasi KATAM yang dapat diakses melalui http://katam.litbang.pertanian.go.id/. Data observasi KATAM ini mengambil sampel data lapangan di Kecamatan Kertajati, Kabupaten Majalengka, sebagai berikut :
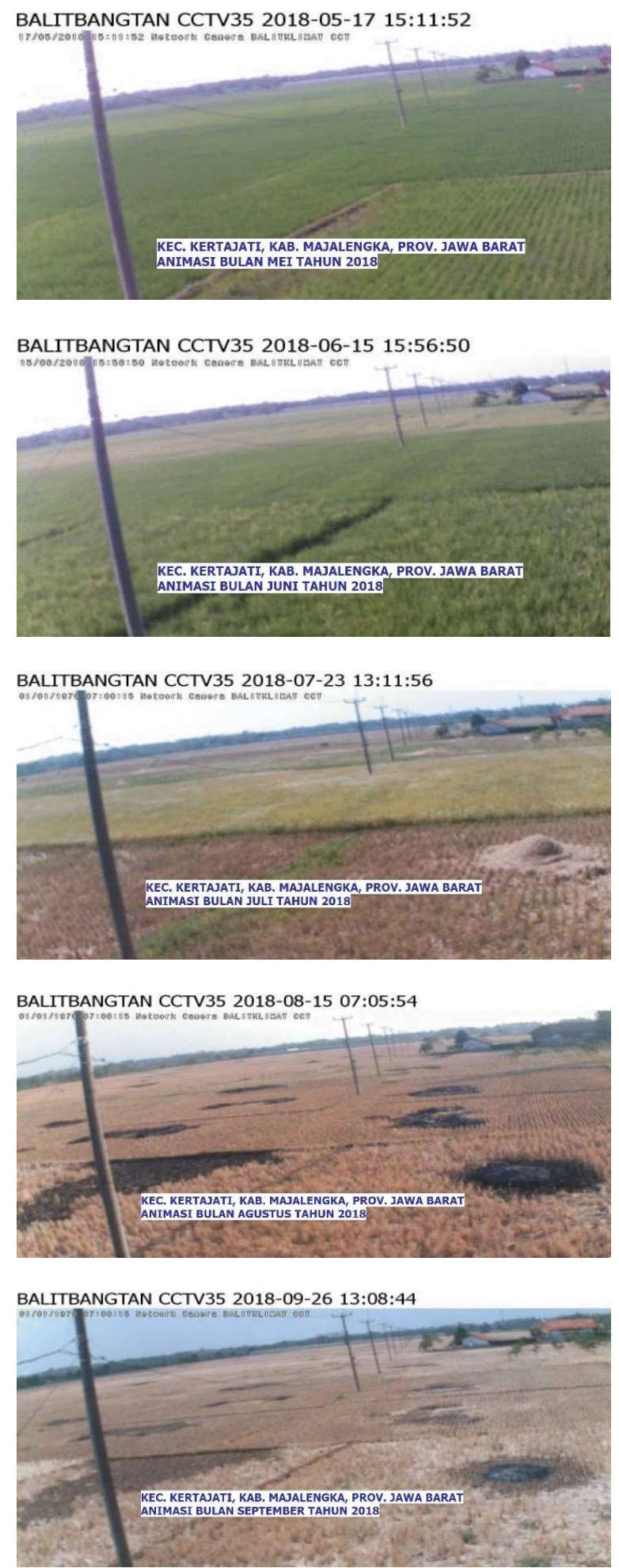

Gambar 4. Data Observasi Fase Tanaman Padi di Kec.Kertajati, Kab.Majalengka 


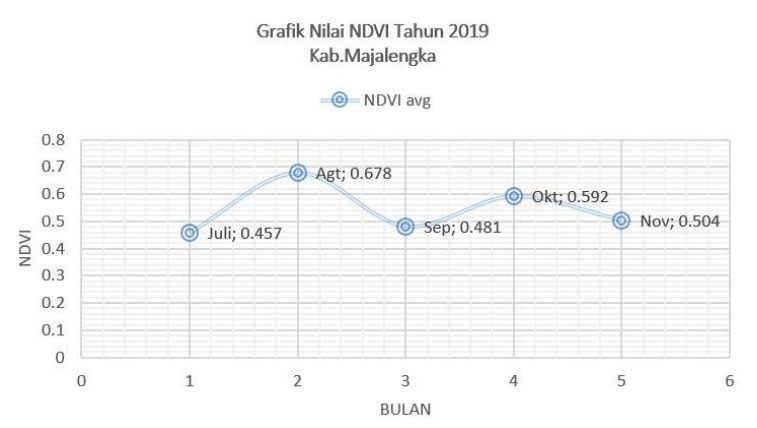

Gambar 5. Grafik NDVI Tahun 2019

Pada tahun 2019, grafik NDVI dapat ditunjukkan melalui Gambar 5. Bulan Juli merupakan fase vegetatif awal padi, bulan Agustus merupakan fase generatif, bulan September merupakan fase panen padi. Bulan Oktober dan bulan November merupakan fase pasca panen padi dimana, sawah dipersiapkan kembali untuk ditanami padi pada bulan selanjutnya.

Berdasarkan hasil dari Grafik NDVI baik di Tahun 2018 dan Tahun 2019, dapat disimpulkan bahwa saat fase vegetatif nilai NDVI padi akan rendah, hal ini dapat disebabkan oleh tanaman padi yang masih terendam air, nilai NDVI akan semakin tinggi dan mencapai puncak saat masa generatif kemudian akan menurun saat fase pematangan padi hingga panen (Cahyono dkk., 2019).

\section{Reklasifikasi NDVI}

Reklasifikasi merupakan klasifikasi dari suatu data agar terbagi menjadi kelas-kelas berdasarkan kebutuhan (Aditiyanti dkk., 2013). Reklasifikasi yang digunakan pada kajian ini terdiri dari 5 kelas yaitu Daerah yang berkategori tidak bervegetasi (Kelas 1), Daerah yang memiliki kehijauan sangat rendah (Kelas 2), Daerah yang memiliki kehijauan rendah (Kelas 3 ), Daerah yang memiliki kehijauan sedang (Kelas 4) dan Daerah yang memiliki kehijauan tinggi (Kelas 5). Adapun sawah yang ada di Kabupaten Majalengka dapat divalidasi melalui Google Earth Pro pada Gambar 6.

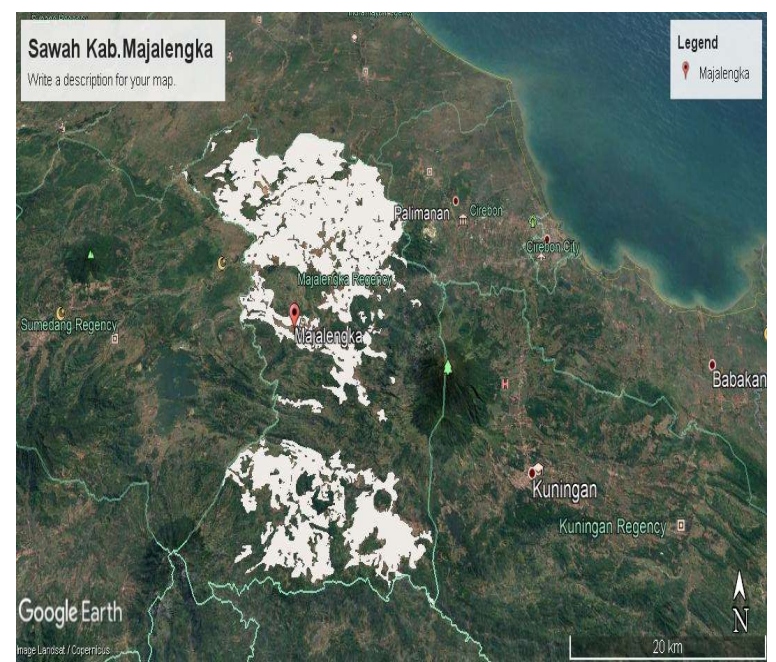

Gambar 6. Lokasi Sawah di Kabupaten Majalengka

Nilai NDVI yang diperoleh kemudian direklasifikasi untuk memperoleh luas daerah termasuk daerah mana yang termasuk vegetasi kering yang berarti belum memasuki masa panen padi, dan daerah mana yang memiliki tingkat kehijauan tinggi yang berarti sedang mengalami masa panen padi atau telah memasuki masa panen padi.

Berdasarkan penjelasan pada bab sebelumnya, Fase generatif terjadi pada bulan Juni 2018 dan bulan Agustus Tahun 2019, dimana memiliki nilai NDVI tinggi yaitu 0,672 dan 0,678 . Berdasarkan penelitian (Browning dkk., 2019) nilai NDVI yang tinggi menunjukkan kondisi tanaman lebih hijau. Fase panen padi tidak memiliki nilai NDVI yang tinggi karena kondisi tanaman padi sudah mulai menguning. Perhitungan dari luas daerah berdasarkan reklasifikasi pada Tahun 2018, ditunjukkan pada Tabel 3.

Tabel 3. Luas Area Tahun 2018 (Sumber : Hasil Analisis)

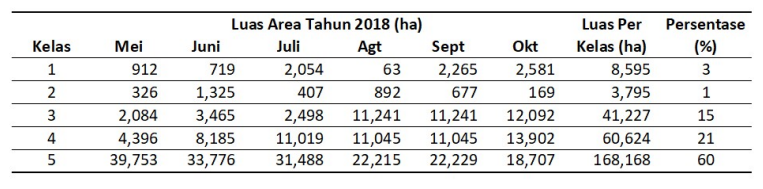

Pada data Tabel 3, wilayah Kabupaten Majalengka yang tidak bervegetasi adalah 3\% dari luas sawah yang di Kabupaten Majalengka, untuk wilayah dengan vegetasi sangat rendah adalah sebesar $1 \%$, wilayah dengan vegetasi rendah adalah 
sebesar $15 \%$, wilayah dengan vegetasi sedang adalah sebesar $21 \%$ dan wilayah yang bervegetasi tinggi atau mengalami fase generatif Tahun 2018 adalah sebesar 60\%. Pada Tahun 2018, Kabupaten Majalengka mengalami musim panen pada bulan Juli, dengan luas daerah 11.019 ha. Pada Gambar 7 ditunjukkan Peta Reklasifikasi saat terjadi musim panen di Kabupaten Majalengka.
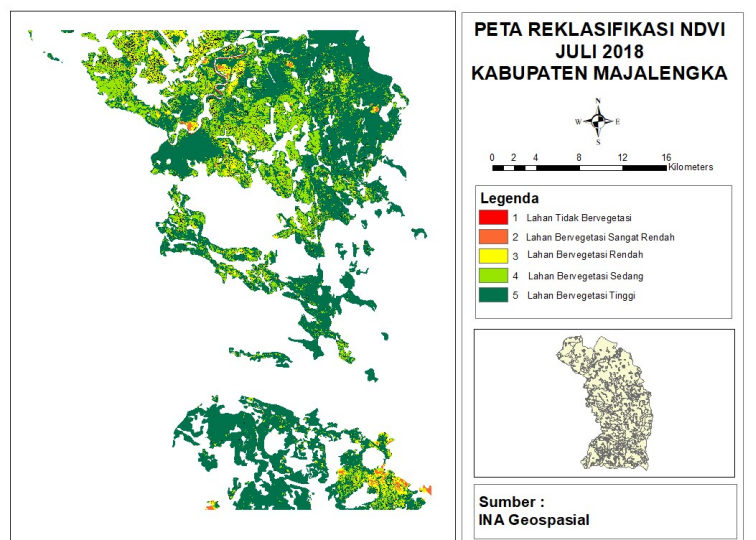

Gambar 7. Peta Reklasifikasi NDVI Juli 2018

Perhitungan dari luas daerah berdasarkan reklasifikasi pada Tahun 2019, dapat dilihat di Tabel 4.

Tabel 4. Luas Area Tahun 2019

\begin{tabular}{crrrrrrrr}
\hline & & \multicolumn{2}{c}{ Luas Area Tahun 2019 (ha) } & \multicolumn{3}{c}{ Luas Per } & Persentase \\
Kelas & \multicolumn{1}{c}{ Juli } & Agt & \multicolumn{1}{c}{ Sept } & Okt & \multicolumn{1}{c}{ Nov } & Kelas (ha) & (\%) \\
\hline 1 & 927 & 2,803 & 2,212 & 2,419 & 1,611 & 9,973 & 4 \\
\hline 2 & 155 & 1,394 & 8,023 & 612 & 8,605 & 18,789 & 8 \\
\hline 3 & 899 & 11,069 & 13,292 & 16,087 & 17,432 & 58,779 & 25 \\
\hline 4 & 4,613 & 13,851 & 10,985 & 11,646 & 7,662 & 48,757 & 21 \\
\hline 5 & 40,884 & 18,337 & 12,940 & 16,686 & 12,147 & 100,994 & 43 \\
\hline
\end{tabular}

Berdasarkan data Tabel 4, Pada Bulan Juli November Tahun 2019, wilayah Kabupaten Majalengka yang tidak bervegetasi adalah $4 \%$ dari luas sawah yang di Kabupaten Majalengka, untuk wilayah dengan vegetasi sangat rendah adalah sebesar $8 \%$, wilayah dengan vegetasi rendah adalah sebesar $25 \%$, wilayah dengan vegetasi sedang adalah sebesar $21 \%$ dan wilayah yang bervegetasi tinggi atau mengalami fase generatif adalah sebesar $43 \%$. Pada Tahun 2019, Kabupaten Majalengka mengalami puncak musim panen pada bulan September, dengan luas daerah sebesar 10.985 ha. Pada Gambar 8 ditunjukkan Peta Reklasifikasi saat terjadi musim panen di Kabupaten Majalengka.

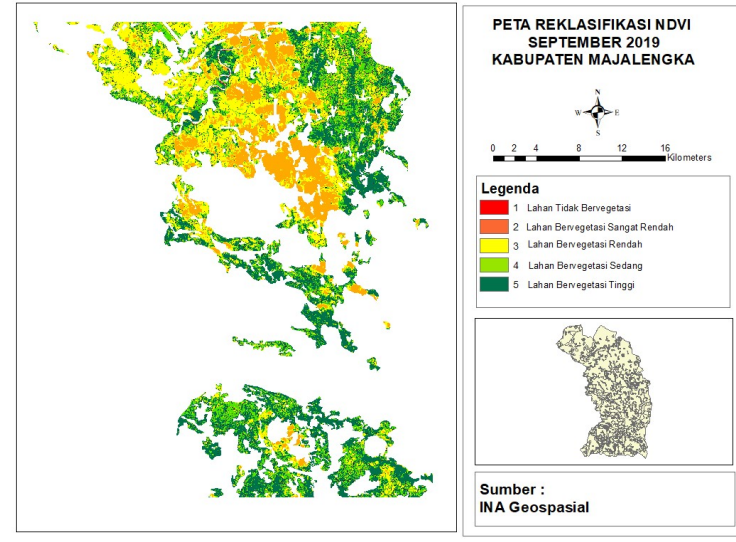

Gambar 8. Peta Reklasifikasi NDVI September 2019

Hasil analisis berdasarkan reklasifikasi NDVI mengacu pada penelitian sebelumnya yang dilakukan oleh Sukmono dkk. (2018). Reklasifikasi pada penelitian ini diolah dengan ArcGis, dengan hasil output berupa luas area dari wilayah yang tidak bervegetasi hingga yang bervegetasi tinggi pada Kabupaten Majalengka di Tahun 2018-2019. Hasil yang diperoleh adalah masa generatif yang ditandai dengan tingginya nilai NDVI menurun, yaitu sebesar 60\% pada Tahun 2018 dan 43\% pada Tahun 2019. Hal ini berpengaruh terhadap luas area panen padi, dimana Tahun 2018 luas panen padi mencakup 11.019 ha dan 10.985 ha pada Tahun 2019. Perhitungan nilai NDVI membantu dalam mendeteksi kekeringan dan membantu petani dalam menentukan fase tanam dan panen padi, agar produksi padi di tahun-tahun selanjutnya tidak terus menurun.

\section{Korelasi Nilai NDVI dengan Hasil Produksi Padi}

Pada kajian penelitian ini dikaitkan korelasi antara nilai NDVI dengan hasil produksi padi di Kabupaten Majalengka. Pada Tabel 5 dapat dilihat jumlah produksi padi Tahun 2018 dan Tahun 2019 ditunjukkan pada Tabel 6 .

Tabel 5. Nilai NDVI dengan Produksi Padi (1) Sumber: Hasil Analisis

\begin{tabular}{|c|c|c|c|c|}
\hline \multicolumn{5}{|c|}{ Produksi } \\
\hline \multirow{2}{*}{$\frac{\text { Bulan }}{5}$} & \multirow{2}{*}{$\frac{\text { NDVI }}{0.493}$} & \multirow{2}{*}{$\begin{array}{l}\text { Padi } \\
24,558\end{array}$} & \multicolumn{2}{|c|}{ Keterangan } \\
\hline & & & Uji Korelasi & 0.130724 \\
\hline 6 & 0.672 & 42,885 & Rsquare & 0.017089 \\
\hline 7 & 0.570 & 124,489 & & \\
\hline 8 & 0.662 & 45,236 & & \\
\hline 9 & 0.713 & 38,827 & & \\
\hline 10 & 0.505 & 8,111 & & \\
\hline
\end{tabular}


Tabel 6. Nilai NDVI dengan Produksi Padi (2) Sumber: Hasil Analisis

\begin{tabular}{|c|c|c|c|c|}
\hline \multicolumn{5}{|c|}{ Produksi } \\
\hline Bulan & NDVI & Padi & Keterangan & \\
\hline 7 & 0.457 & 134,865 & Uji Korelasi & -0.1463 \\
\hline 8 & 0.678 & 71,962 & Rsquare & 0.021404 \\
\hline 9 & 0.481 & 15,550 & & \\
\hline 10 & 0.592 & 6,931 & & \\
\hline 11 & 0.504 & 14,468 & & \\
\hline
\end{tabular}

Hasil produksi padi paling besar terjadi pada bulan Juli, pada Tahun 2018 sebesar 124.489 ton dan pada Tahun 2019 sebesar 134.865 ton. Adapun Korelasi antara kedua variabel tersebut pada Tahun 2018 dapat ditunjukkan pada Gambar 9 dan pada Tahun 2019 ditunjukkan pada Gambar 10.

Korelasi Nilai Produksi Padi dengan NDVI Bulanan Tahun 2018

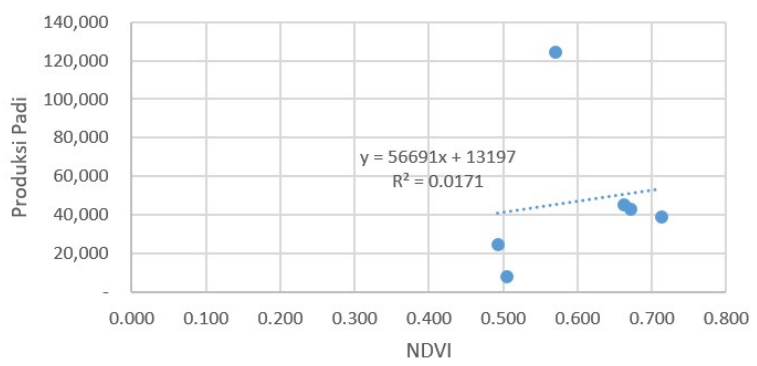

Gambar 9. Diagram Scatter Nilai NDVI dengan Produksi Padi Tahun 2018

Korelasi Nilai Produksi Padi dengan NDVI Bulanan Tahun 2018

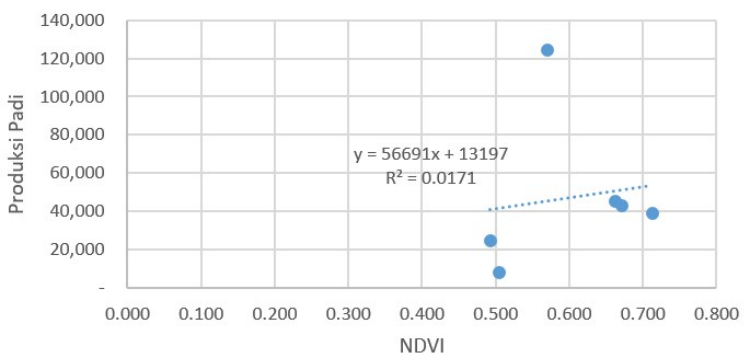

Gambar 10. Diagram Scatter Nilai NDVI dengan Produksi Padi Tahun 2019

Pada penelitian ini, dilakukan perhitungan manual uji korelasi dan diagram pencar (scatterplot) dibuat melalui Microsoft Excel. Dengan bantuan fungsi formula =PEARSON untuk mengetahui nilai korelasi dan formula =Rsqure untuk melihat nilai koefisien determinasi. Dari penelitian ini diperoleh pada Tahun 2018 besar korelasi adalah 0.130724 dan diperoleh nilai $\mathrm{R}^{2}$ (Koefisien Determinasi) sebesar 0,017089. Berdasarkan hasil tersebut dapat diketahui variabel NDVI dalam penelitian ini hanya mampu menjelaskan variabel produksi padi sebesar $1,7 \%$, sementara itu dari uji korelasi dapat dilihat bahwa hubungan antar variabel NDVI dan produksi padi memiliki korelasi sangat lemah karena nilainya mendekati 0. Pada Tahun 2019, nilai korelasinya sebesar -0.1463 dan nilai koefisien determinasi adalah 0.021404, korelasi antara nilai NDVI dan hasil produksi padi pada Tahun 2019 adalah bernilai negatif, hal ini berarti korelasi antar kedua variabel berlawanan. Variabel NDVI dalam penelitian ini hanya mampu menjelaskan variabel produksi padi sebesar $2 \%$.

Berdasarkan uji korelasi antara dua variabel tersebut dapat diambil kesimpulan bahwa korelasi antara kedua variabel pada Tahun 2018 masih bernilai positif yang berarti hubungan antar kedua variabel masih searah meskipun sangat lemah. Akan tetapi pada Tahun 2019 korelasi antar keduanya sangat lemah dan berlawanan (Aditiyanti dkk., 2013). Apabila terjadi kondisi berlawanan dapat berarti ada saat dimana nilai NDVI kecil (tidak di saat masa generatif), hasil produksi padinya besar. Hal ini sesuai dengan penjelasan yang dilakukan sebelumnya karena masa panen tidak berada di puncak tertinggi NDVI (Adinda dkk., 2020; Browning dkk., 2019).

\section{Korelasi Nilai NDVI dengan Curah Hujan Bulanan}

Pada penelitian ini juga menilai korelasi antara nilai NDVI dengan curah hujan. Tahun 2018 besar Curah Hujan ditunjukkan pada Tabel 7 dan pada Tahun 2019 ditunjukkan pada Tabel 8.

Tabel 7. Nilai NDVI dengan Curah Hujan (1) (Sumber : Hasil Analisis)

\begin{tabular}{rcclll}
\hline \multicolumn{1}{c}{ Bulan } & CH & NDVI & \multicolumn{2}{c}{ Keterangan } \\
\hline 5 & 0 & 0.493 & Uji Korelasi & 0.263032 \\
\hline 6 & 32 & 0.672 & Rsquare & 0.069186 \\
\hline 7 & 0 & 0.570 & & \\
\cline { 1 - 3 } 8 & 0 & 0.662 & & \\
\cline { 1 - 3 } 9 & 1 & 0.713 & & \\
\hline 10 & 8 & 0.505 & & \\
\hline
\end{tabular}


Tabel 8. Nilai NDVI dengan Curah Hujan (2) (Sumber: Hasil Analisis)

\begin{tabular}{rcclll}
\hline \multicolumn{1}{c}{ Bulan } & CH & NDVI & \multicolumn{2}{c}{ Keterangan } \\
\hline 7 & 0 & 0.457 & Uji Korelasi & -0.23497 \\
\hline 8 & 0 & 0.678 & Rsquare & 0.05521 \\
\hline 9 & 0 & 0.481 & & \\
\cline { 1 - 3 } 10 & 0 & 0.592 & & \\
\cline { 1 - 3 } 11 & 68.3 & 0.504 & & \\
\cline { 1 - 3 } & & & & &
\end{tabular}

Tahun 2018, curah hujan bulanan tertinggi terjadi pada bulan Juni yaitu sebesar $32 \mathrm{~mm}$ dan Tahun 2019 terjadi pada bulan November yaitu sebesar 68,3 mm. Adapun Korelasi antara kedua variabel tersebut ditunjukkan pada Gambar 11 dan Gambar 12.

Korelasi Nilai NDVI dengan Curah Hujan Bulanan Tahun 2018

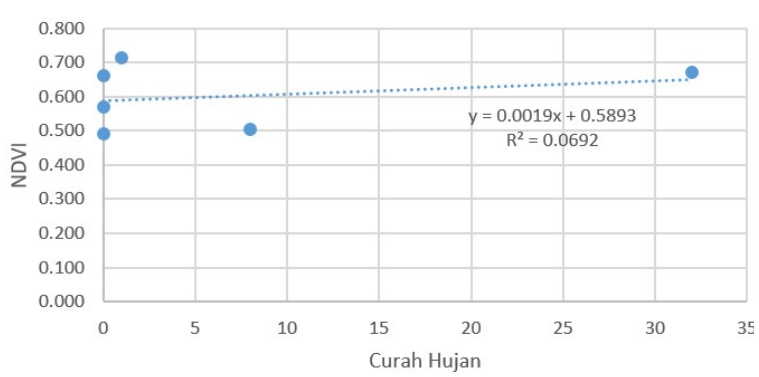

Gambar 41. Diagram Scatter Nilai NDVI dengan Curah Hujan Bulanan Tahun 2018

Korelasi Nilai NDVI dengan Curah Hujan Bulanan Tahun 2019

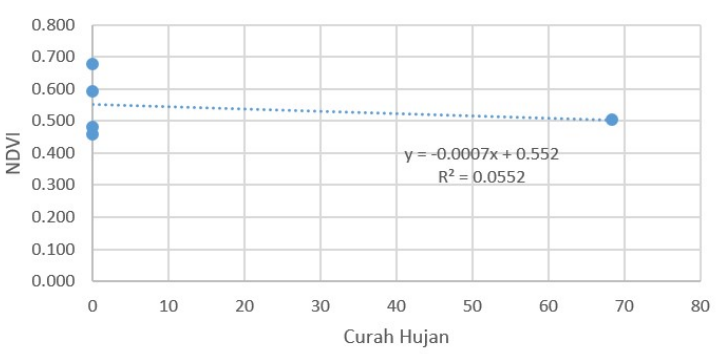

Gambar 32. Diagram Scatter Nilai NDVI dengan Curah Hujan Bulanan Tahun 2019

Pada Tahun 2018 nilai korelasinya sebesar 0,263032 dan nilai koefisien determinasi adalah 0,069186 dan Pada Tahun 2019 nilai korelasinya sebesar -0,23497 dan nilai koefisien determinasi adalah 0,05521. Berdasarkan hasil tersebut dapat diketahui variabel curah hujan dalam penelitian ini hanya mampu menjelaskan variabel NDVI sebesar $6 \%$, sementara itu dari uji korelasi dapat dilihat bahwa hubungan antar variabel curah hujan dan
NDVI memiliki korelasi lemah. Sementara itu pada Tahun 2019, korelasi antara ni curah hujan dan NDVI bernilai negatif, hal ini berarti korelasi antar kedua variabel berlawanan. Variabel curah hujan dalam penelitian ini hanya mampu menjelaskan variabel NDVI sebesar $5 \%$

Dari pengolahan tersebut dapat disimpulkan berdasarkan uji korelasi antara dua variabel tersebut dapat diambil kesimpulan bahwa korelasi antara kedua variabel pada tahun 2018 masih bernilai positif yang berarti hubungan antar kedua variabel masih searah meskipun lemah. Akan tetapi pada Tahun 2019 korelasi antar keduanya lemah dan berlawanan (Aditiyanti dkk., 2013). Apabila terjadi kondisi berlawanan dapat berarti ada saat dimana nilai curah hujan kecil, Nilai NDVI besar. Curah hujan termasuk variabel yang mempengaruhi nilai NDVI tetapi bukan variabel yang dominan karena korelasi antar keduanya yang lemah. Meskipun curah hujan bukan merupakan variabel yang dominan dalam pengelolaan air di sawah, kebutuhan akan air tetap harus diperhatikan karena tanaman padi merupakan tanaman yang membutuhkan pasokan air irigasi dalam jumlah cukup, kebutuhan air tersebut tidak selalu berdasarkan air hujan. Agar saat terjadi kekeringan karena bergesernya musim hujan, tanaman padi tetap bisa berproduksi untuk menjaga stabilitas ketahanan pangan (Putri, 2018).

\section{PENUTUP}

\section{Simpulan dan Saran}

Saat memasuki fase vegetatif nilai NDVI padi akan rendah, hal ini dapat disebabkan oleh tanaman padi yang masih terendam air, nilai NDVI akan semakin tinggi dan mencapai puncak saat masa generatif kemudian akan menurun saat fase pematangan padi hingga panen. Pada penelitian ini puncak musim panen pada bulan Juli di Tahun 2018, dan bulan September di Tahun 2019. Berdasarkan perhitungan reklasifikasi dari nilai NDVI, diperoleh luas daerah yang mengalami musim panen pada bulan Juli adalah sebesar 11.019 ha di Tahun 2018 dan pada bulan September, dengan luas daerah sebesar 10.985 ha di Tahun 2019. Perhitungan nilai 
NDVI membantu dalam mendeteksi kekeringan dan membantu petani dalam menentukan fase tanam dan panen padi, agar produksi padi di tahun-tahun selanjutnya tidak terus menurun.

Uji korelasi yang dilakukan baik antara NDVI dan produksi padi maupun curah hujan dan NDVI menunjukkan hubungan yang sangat lemah dan lemah. Kebutuhan air tetap harus diperhatikan karena tanaman padi meskipun korelasi keduanya lemah agar saat terjadi kekeringan karena bergesernya musim hujan, kebutuhan air pada tanaman padi tetap cukup.

Saran yang dapat dianjurkan untuk penelitian selanjutnya adalah apabila data produksi padi dapat diperoleh lebih lengkap, dapat dihitung time-series dari nilai NDVI, sehingga lebih terlihat pola masa panen padi dari tahun ke tahun. Kekurangan dari penelitian ini adalah pelaksanaan studi lapangan direncanakan pada tahun 2020, akan tetapi bertepatan saat awal pandemi COVID-19, yang mengakibatkan terbatasnya data observasi langsung. Oleh karena itu tersedianya data KATAM membantu peneliti dalam memvalidasi hasil penelitian dengan keadaan di lapangan.

\section{Ucapan Terima Kasih}

Penulis mengucapkan terimakasih kepada pada pengampu Kuliah Lapang di Departemen Geografi Universitas Indoesia yang telah berkontribusi dalam menyelesaikan penelitian ini.

\section{DAFTAR PUSTAKA}

Adinda, R., Rusdi, M. dan Sugianto, S. (2020), "Pemanfaatan Indeks Vegetasi NDVI Terhadap Siklus Phenology Tanaman Padi Pada Musim Gadu 2017", Jurnal Ilmiah Mahasiswa Pertanian, Vol.5, No.2, hal. 301-309. http://doi.org/10.17969/jimfp.v5i2.14873.

Aditiyanti, A.H., Sabri, L.M. dan Sasmito, B. (2013), "Analisis Pengaruh Perubahan NDVI Dan Tutupan Lahan Terhadap Suhu Permukaan Di Kota Semarang", Jurnal Geodesi Undip, Vol.2, No.3. Diambil dari https://ejournal3.undip.ac.id/index.php/geodesi/arti cle/view/3713.
Aji, B.J.P.S., Prasetyo, Y., dan Hani'ah (2017), "Analisis Tingkat Produksi Padi dan Perhitungan Logistik Pangan Berdasarkan Metode EVI (Enhanced Vegetation Index) dan NDVI (Normalized Difference Vegetation Index) Menggunakan Citra Sentinel-2 Tahun 2016 (Studi Kasus: Kabupaten Klaten, Jawa Tengah)", Jurnal Geodesi Undip, Vol.6, No.4, hal. 263273.

Badan Pusat Statistik (2020), Produksi Padi di Jawa Barat pada 2019 sebesar 9,08 juta ton Gabah Kering Giling (GKG). Diambil dari https://jabar.bps.go.id/pressrelease/2020/03/02/817 /produksi-padi-di-jawa-barat-pada-2019-sebesar-908-juta-ton-gabah-kering-giling--gkg.html\#: :text=Produksi\%20padi\%20di\%20Jawa\%20Ba rat\%20pada\%202019\%20diperkirakan\%20sebesar\%2 09,83\%20persen\%20dibandingkan\%20tahun\%20201 8.

Browning, D.M., Snyder, K.A. dan Herrick, J.E. (2019), "Plant Phenology: Taking the Pulse of Rangelands", Rangelands, Vol.41, No.3, hal. 129-134. http://doi.org/10.1016/j.rala.2019.02.001.

Cahyono, B.E., Nugroho, A.T. dan Arifilla, A. (2019), "Analisis Usia Tanaman Padi Berdasarkan Nilai NDVI Menggunakan Citra Landsat 8 (Studi Kasus: Desa Rambigundam Kecamatan Rambipuji Jember )", Lecturer Scientific Publication, Diambil dari http://repository.unej.ac.id/handle/123456789/9703 8.

Chander, G., Markham, B.L. dan Helder, D.L. (2009), "Summary of Current Radiometric Calibration Coefficients for Landsat MSS, TM, ETM+, and EO-1 ALI Sensors", Remote Sensing of Environment, Vol.113, No.5, hal. 893-903. http://doi.org/10.1016/j.rse.2009.01.007.

Dawe, D., Frolking, S. dan Li, C. (2004), "Trends in RiceWheat Area in China", Field Crops Research, Vol.87, No.1, hal. 89-95. http://doi.org/10.1016/j.fcr.2003.08.008.

Ghaleb, F., Mario, M. dan Sandra, A.N. (2015), "Regional Landsat-Based Drought Monitoring from 1982 to 2014", Climate, Vol.3, No.3, hal. 563-577. http://doi.org/10.3390/cli3030563.

Huwaydi, Y. dan Persada, S.F. (2018), "Analisis Deskriptif Pengguna Go-Pay Di Surabaya", Jurnal Teknik ITS, Vol.7, No.1, hal. A55-A59. http://doi.org/10.12962/j23373539.v7i1.28827. 
Iswari, A.R., Hani'ah, H. dan Nugraha, A.L. (2017), "Analisis Fluktuasi Produksi Padi Akibat Pengaruh Kekeringan di Kabupaten Demak", Jurnal Geodesi Undip, Vol.5, No.4, hal. 233-242.

Julianto, F.D., Putri, D.P.D. dan Safi'i, H.H. (2020), "Analisis Perubahan Vegetasi Dengan Data Sentinel-2 Menggunakan Google Earth Engine", Jurnal Penginderaan Jauh Indonesia, Vol.2, No.2, hal. 13-18.

Khosravi, H., Haydari, E., Shekoohizadegan, S. dan Zareie, S. (2017), "Assessment the Effect of Drought on Vegetation in Desert Area Using Landsat Data", The Egyptian Journal of Remote Sensing and Space Science, Vol.20, hal. S3-S12. http://doi.org/10.1016/j.ejrs.2016.11.007.

Prasetyo, D.A., Suprayogi, A. dan Hani'ah, H. (2018), "Analisis Lokasi Rawan Bencana Kekeringan Menggunakan Sistem Informasi Geografis Di Kabupaten Blora Tahun 2017", Jurnal Geodesi Undip, Vol.7, No.4, hal. 314-324.

Pratiwi, E.P.A., Ramadhani, E.L., Nurrochmad, F. dan Legono, D. (2020), "The Impacts of Flood and Drought on Food Security in Central Java", Journal of the Civil Engineering Forum, Vol.6, No.1, hal. 69-78. http://doi.org/10.22146/jcef.51872.

Putri, I.M. (2018), "Kebijakan Pemerintah Daerah Dalam Pencegahan Bencana Kekeringan Di Indramayu", Logika : Jurnal Penelitian Universitas Kuningan, Vol.9, No.02, hal. 65-71. http://doi.org/10.25134/logika.v9i02.2488.

Shao, Y., Fan, X., Liu, H., Xiao, J., Ross, S., Brisco, B., Brown, R. dan Staples, G. (2001), "Rice Monitoring and Production Estimation Using Multitemporal RADARSAT", Remote Sensing of Environment, Vol.76, No.3, hal. 310-325. http://doi.org/10.1016/S00344257(00)00212-1.

Sukmono, A., Rahman, F. dan Yuwono, B.D. (2018), "Pemanfaatan Teknologi Penginderaan Jauh untuk Deteksi Kekeringan Pertanian Menggunakan Metode Normalized Difference Drought Index di Kabupaten Kendal", Jurnal Geografi: Media Informasi Pengembangan dan Profesi Kegeografian, Vol.14, No.2, hal. 57-65. http://doi.org/10.15294/jg.v14i2.11521.

Widyastuti, R. (2020), "Pola Sebaran Kekeringan di Kecamatan Simpenan Menggunakan Metode SPI (Standardized Precipitation Index)", Jurnal
Geosaintek, Vol.6, No.1, hal. 19-24. http://doi.org/10.12962/j25023659.v6i1.6272. 